Original Research Paper

\title{
Strengthening of Laminated Glass Windows against Windborne Debris Impact
}

\author{
${ }^{1}$ Xihong Zhang, ${ }^{2 *}$ Qingfei Meng, ${ }^{3}$ Chiara Bedon and ${ }^{4}$ Piotr W. Sielicki \\ ${ }^{1}$ Centre for Infrastructure Monitoring and Protection, \\ School of Civil and Mechanical Engineering, Curtin University, Australia \\ ${ }^{2}$ School of Civil and Environmental Engineering, University of Technology, Sydney, Australia \\ ${ }^{3}$ Department of Engineering and Architecture, University of Trieste, Trieste, Italy \\ ${ }^{4}$ Poznan University of Technology, Poznan, Poland
}

\author{
Article history \\ Received: 08-09-2020 \\ Revised: 27-10-2020 \\ Accepted: 29-10-2020 \\ Corresponding Author: \\ Qingfei Meng \\ School of Civil and \\ Environmental Engineering, \\ University of Technology, \\ Sydney, Australia \\ Email: qingfei.meng@uts.edu.au
}

\begin{abstract}
This paper presents numerical modelling to study potential mitigation methods to improve the impact resistance performance of laminated glass windows against timber windborne debris impact. A detailed numerical model of laminated glass window is generated and validated with laboratory impact tests. The influence of supporting frames made of different stiffness materials is examined. Numerical simulation shows that boundary condition has limited influence to the penetration resistance of laminated glass windows. Then, the dynamic response of doubly laminated glass windows of the same total thickness as that of singly laminated glass windows is studied, which finds that optimization of glass and interlayer layout could effectively improve the penetration resistance of laminated glass windows.
\end{abstract}

Keywords: Laminated Glass, Windborne Debris, Impact, Mitigation

\section{Introduction}

In cyclone-prone regions, windborne debris impact poses a major threat to structure and personnel safety in the wake of cyclone incidents. Comparing with other structural elements, glass windows is a most fragile component of the entire structure envelop which therefore needs to be specially designed against debris impact (Fig. 1). Post-investigation on hurricanes in Houston, Texas, USA (Beason, 1974; Beason and Morgan, 1984) reported large scale window failures that were contributed to windborne debris. The penetration and failure of glass windows in cyclone events has also been cited as one of the reasons leading to the overturn and collapse of low-rise residential buildings. After 1974 Cyclone Tracy in Darwin, Australia researchers found that windborne debris contributed to large-scale damage to structure (Walker, 1991). As illustrated in Fig. 2, fractured glass windows by windborne debris impact creates an opening in the structure envelop, which results in the internal wind pressure to quickly increase and double the wind load acting on the roof and surrounding walls. Moreover, occupants inside buildings are also under the threats of flying glass shards from the broken windows according to the post-investigation after cyclone events. Therefore, a study on the response and mitigation of glass windows/façade against windborne debris impact is an important and necessary topic for the protection of structures and personnel safety particularly for cyclone-prone regions.

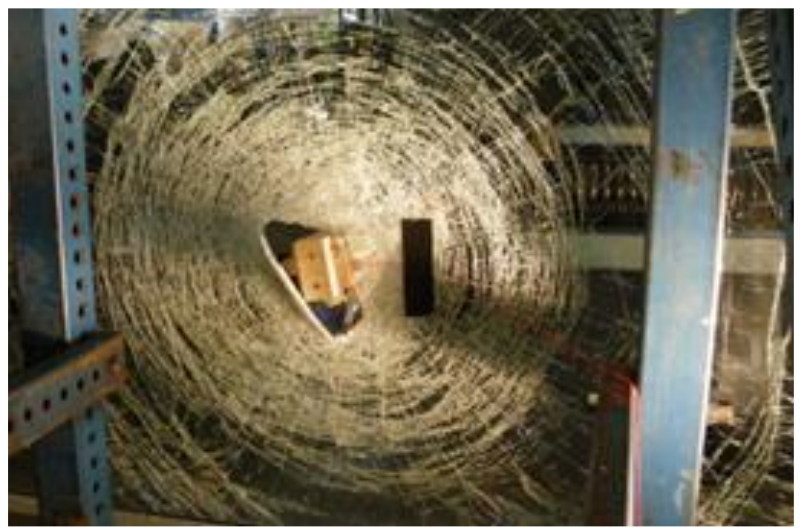

Fig. 1: Damage of laminated glass windows under windborne debris impact 


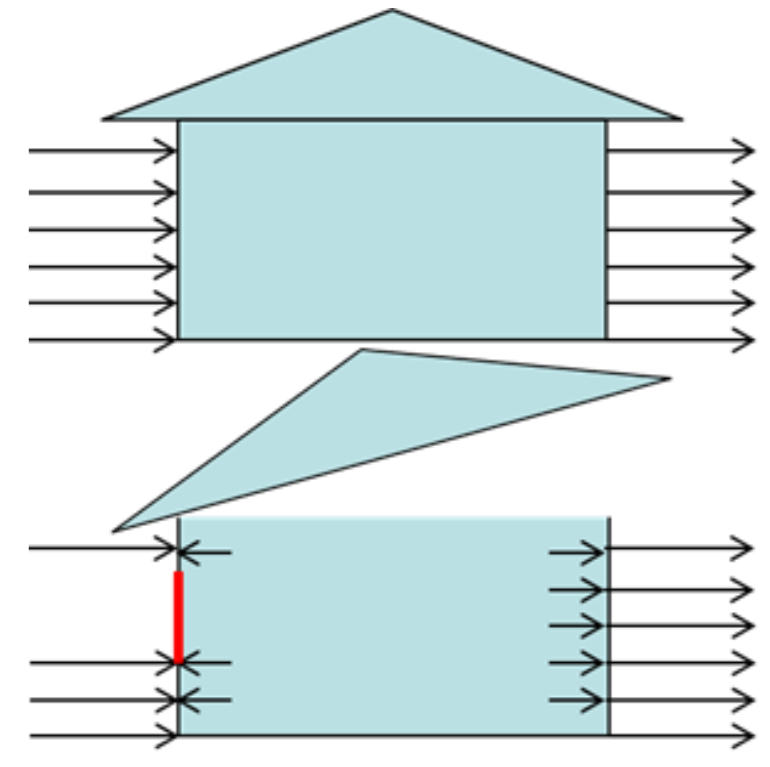

Fig. 2: Structure damage due to failure of windows in cyclones

Windborne debris can be categorized into two types according to the mass and elastic modulus properties. One is a small rigid missile-like rock fragments and roof gravels. The other one is the large soft objects like wooden debris which are the main source of windborne debris. In the observation of post-event investigation, timber debris from loose wooden structures and broken tree trunks has been found to be the dominant types of windborne debris especially in urban areas (Minor et al., 1977). Many design standards require proper design of window system subjected to windborne debris impact in cyclone-prone regions in different countries. For example, the Defense Civil Preparedness Agency in America suggests a $7 \mathrm{~kg}$ timber plank with $100 \mathrm{~mm}$ by 50 $\mathrm{mm}$ frontal area as projectile when designing structural elements as tornado shelters (US Govt. Print. Off. 1975). The US Department of Energy (Coats, 1985) and Standard Building Code SBCCI, 1983 both specify a $7 \mathrm{~kg}$ wood block flying at $15 \mathrm{~m} / \mathrm{s}$ at debris projectile. In the wake of Cyclone Tracy in 1974, (Standards Association of Australia, 2002) requires all structural elements in cyclone-prone areas to be able to bear the impact of a $4 \mathrm{~kg}$ timber block impacting at $15 \mathrm{~m} / \mathrm{s}$. Later in the revision in 2011, the required debris impact speed has been increased to 0.4 times of the design wind speed in the horizontal direction and 0.1 times of the design wind speed in a vertical direction, which means the speed of timber debris can be over $40 \mathrm{~m} / \mathrm{s}$ in extreme case (2012). Therefore, it is necessary to develop an effective mitigation retrofit to improve glass window resistant capacity against further increased loading requirement.

Glass windows normally uses annealed float glass which is produced by the standard float process. It is the first product of the manufacturing process. Also, it is considered as a primary and economical glass type due to its comparatively simple manufacturing process and method. Annealed glass shows linear elastic and brittle behaviour before it reaches the fracture point. Theoretically speaking, the tensile strength of glass can exceed 21GPa (Overend et al., 2007), however float annealed glass which is generally used for residential and commercial building would crack at a level below $100 \mathrm{MPa}$ due to existing flaws on the glass pane surface (Griffith, 1921). Different researches and studies on static tensile strengths of float annealed glass indicated a significant variation on results because of different surface conditions, different chemical compositions and different testing methods (CEN/TC129). The mechanical properties of annealed glass also show strain rate sensitivity. For example, about $30 \%$ increase in glass strength was reported by Zhang and his co-workers (Zhang et al., 2012; Zhang and Hao, 2016) through Split-Hopkinson Pressure Bar tests. This is because under static load, flaws on the glass surface strongly influences glass strength, which nevertheless becomes a minor when the glass is under dynamic loading condition (Dandekar and Beaulieu, 1995; Alexander et al., 2008; Grady and Chhabildas, 1996).

To improve the resistant capacity of glass windows under extreme loading environment, different materials and techniques have been developed and proposed (Bedon et al., 2018; Zhang and Bendon, 2017). Among all these methods, laminated glass is one of the most commonly adopted strategies because of simplicity and economic features. Laminated glass consists typically of two or more glass plies attached by one or more slices of interlayers. After the glass plies break, the interlayer holds the crushed glass shards together and dissipate the imposed energy through its deformation and laminated pane vibration. Many studies have been carried out to investigate the impact response of laminated glass panels, which include simplified analytical derivation (Yuan et al., 2017), laboratory experiments (Zhang and Hao, 2011; Zhang et al., 2013a) and numerical simulations (Zhang et al., 2012). Various numerical methods have been adopted to model the response of laminated glass under impact loading, which includes but not limited to finite element method (Zhang et al., 2012), boundary-element method (Wei et al., 2006), SPH method (Oda and Zang, 1998; Zang et al., 2007; 2010). A general shortcoming is that most existing numerical models utilized static material properties for glass and interlayer, which nevertheless have been found to behave very differently under dynamic loading as compared to that under static conditions. To the authors' knowledge, a number of experiments have been conducted on laminated glass windows under impact loading. However, most of these studies were only to 
prove the impact resistance of a particular product or to validate particular concept and the testing results were therefore not publicly accessible.

Recently, (Zhang and Hao, 2011; Zhang et al., 2013a) conducted a comprehensive study on the vulnerability of laminated glass under windborne debris impact through laboratory impact test and detailed numerical simulation. Through parametric study, it was found that increasing glass pane thickness could help to reduce global deflection of the entire laminated glass pane. This is because the increased glass pane thickness provides better inertia resistance. In addition, increasing Polyvinyl Butyral (PVB) interlayer thickness would effectively reduce penetration caused by timber debris impact because of the outstanding deformation capacity of PVB. Moreover, in the numerical model window boundary condition was also found to influence the performance of the laminated glass pane (Zhang et al., $2013 \mathrm{~b})$. This is because with a pinned boundary, the laminated pane is more flexural and the forced vibration due to debris impact is de-amplified. The preliminary finding was migrated to laminated glass windows against blast loading. In a following study, (Zhang et al., 2015c) introduced a sliding boundary to laminated glass windows, which enables the transitional movement of the glass pane in the direction of loading (Biggs, 1964). Through numerical simulation and experimental validation, it was found that the new sliding frame could effectively improve the performance of the laminated glass window against blast loading. Therefore, there is potential that by improving the window frame condition might also enhance the impact-resistant performance of laminated glass windows against windborne debris.

This study intends to perform numerical simulation to investigate two possible mitigation retrofits for laminated glass windows against windborne debris impact: (a) Improvement of window frame boundary condition by using rubber bearing of different stiffness so as to improve the dynamic response of laminated glass windows under impact loading; and (b) preliminary optimization of glass plies and interlayer layouts. A detailed three-dimensional numerical model for laminated glass windows under timber projector impact is generated and the performance of the windows is examined in details.

\section{Numerical Modelling}

\section{Model Setup}

Numerical modelling is conducted with commercial software LS-DYNA (Hallquist, 2014). Figure 3 illustrates the laminated glass windows generated which comprises of a laminated glass pane, window frame with rubber inserts, timber projectile. Following previous study on laminated glass and structural elements against windborne debris impact (Zhang and
Hao, 2011; Zhang et al., 2013a; Meng et al., 2016a; 2016b), a three-dimensional solid model gives a detailed response of laminated glass under impact loading. A quarter of the window is considered in the model due to symmetry. 8-node SOLID 164 element with full integration is utilized. Mesh convergence study was performed as in reference (Zhang et al., 2012) and $5 \times 5$ $\mathrm{mm}$ mesh is selected for the laminated glass pane and window frame with converged results. In the thickness direction, glass and PVB interlayer are meshed with two layers. The contacting layer of the timber projectile is meshed to the same size of the glass pane and the rest is meshed with gradually increased element sizes. Erosion technique is used to avoid mesh tangling particularly for PVB interlayer.

Two window dimensions, namely $2000 \times 1100 \mathrm{~mm}$ ("size A", in the following) and $1000 \times 600 \mathrm{~mm}$ ("size B") are modelled in this study, which represent typical glass door and glass window for residential structures in cyclone-prone regions. A single laminated glass window comprising two glass panes sandwiching a PVB interlayer is generated as conventional laminated glass pane (Fig. 3b). Another type of laminated pane with triple glass panes and double layers of PVB interlayers (Fig. 3c) is also developed as the other mitigation retrofit to optimize the layout of the window pane.

To define the interactions between different components of laminated glass window, the contact option AUTOMATIC SURFACE TO SURFACE in LSDYNA is used with static friction coefficient of 0.7 and dynamic friction coefficient of 0.5 to simulate the interaction between glass and window frame. The inner window frame is initially fixed. Observation in laboratory impact tests on laminated glass found that delamination hardly occurred between fractured glass and PVB interlayer. Glass debonding from PVB layer is therefore not modelled. The contact nodes between PVB and glass are merged together. This simplification helps to improve the computation efficiency.

\section{Material Model}

Glass

Glass is a brittle material which is also strain rate sensitive as mentioned above. In this study, Johnson Holmquist Ceramic material model (JH2) is used for glass material. It considers both strain rate effect and material damage. The strength of glass is described as a function of intact strength, fracture strength and damage level. The strength of glass is depicted by a function as follows:

$\sigma^{*}=\sigma_{i}^{*}-D\left(\sigma_{i}^{*}-\sigma_{f}^{*}\right)$

where, $\sigma_{i}^{*}$ is the normalized intact strength, $\sigma_{f}^{*}$ is the normalized fracture strength and $D$ is a damage scalar 
(with $0 \leq D \leq 1$ ). All the normalized stresses have the general form of $\sigma_{i}^{*}=\sigma \sigma^{H E L}$, where $\sigma^{H E L}$ is the equivalent stress at Hugoniot Elastic Limit (HEL). The normalized intact strength and fractured strength are given by:

$$
\sigma_{i}^{*}=A\left(P^{*}+T^{*}\right)^{N}\left(1+C \ln \dot{\varepsilon}^{*}\right)
$$

and:

$$
\sigma_{f}^{*}=B\left(P^{*}\right)^{M}\left(1+C \ln \dot{\varepsilon}^{*}\right)
$$

where, $A, B, C, M$ and $N$ are material constants; $P^{*}$ stands for the normalized pressure; $\dot{\varepsilon}^{*}$ is the actual strain rate over the reference strain rate $\left(1.0 \mathrm{~s}^{-1}\right)$. The damage for fracture is accumulated and expressed as:

$$
D=\sum \Delta \varepsilon_{P} / \varepsilon_{p}^{f}
$$

where, $\Delta \varepsilon_{P}$ is the plastic strain during integration and $\varepsilon_{p}^{f}$ is the plastic strain to fracture under constant pressure $P$. $\mathrm{JH} 2$ model includes plastic strain to define material damage and fracture. Experimental investigation indicates that glass exhibits linear elastic behaviour under static compression. Recently studies on glass dynamic compressive strength using Split Hopkinson
Pressure Bar (SHPB) tests show slightly modulus degradation before glass fracture (Zhang et al., 2012). This plasticity nevertheless is very insignificant. This work emphasis on glass panel response under impact loading, where tensile strength dominates glass failure. Glass compressive plasticity is less important. Since there is no better glass dynamic material model available, JH2 model is used here in the study.

The hydrostatic pressure is determined by:

$$
P=K_{1} \mu+K_{2} \mu^{2}+K_{3} \mu^{3}+\Delta P
$$

where, $K_{1}, K_{2}, K_{3}$ are constants and $\mu=\rho \rho_{0}-1$, in which $\rho$ is the current density and $\rho_{0}$ the initial density, $\Delta P$ is pressure increment.

JH2 model was initially developed to model the ballistic response of ceramic material. Based on recent experimental study on dynamic material properties for glass, (Zhang et al., 2015a) have derived material parameters commercially used window glass (annealed float glass), which has much lower strength due to surface flaws as compared to finely grinded ceramic glass armour. Previous numerical simulations using the modified $\mathrm{JH} 2$ model proved it could prove reasonably good results of glass window response (Zhang et al., 2012).

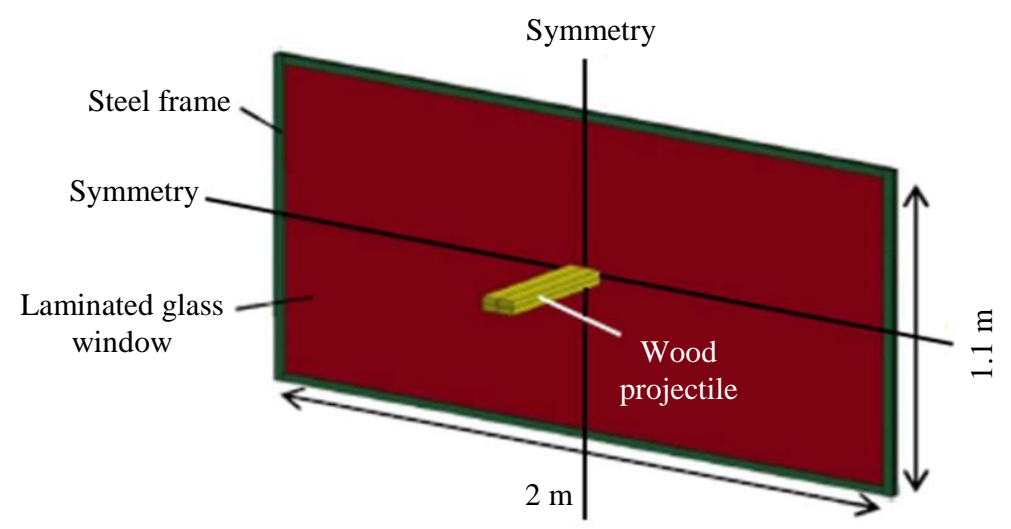

(a)

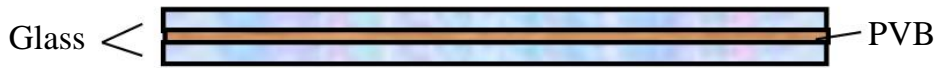

(b)

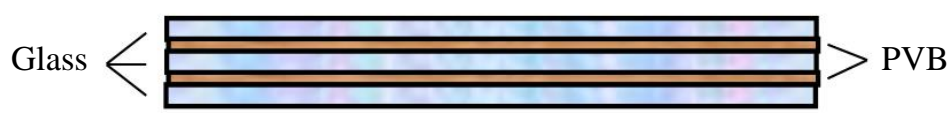

(c)

Fig. 3: Schematic view of the glass window system and laminated glass panes; (a) Mirrored glass window system; (b) Singly laminated glass pane; (c) Doubly laminated glass pane 


\section{$P V B$}

Recent laboratory tests found that the mechanical properties of PVB are very strain rate sensitive (Zhang et al., 2015b; Hooper et al., 2012; Morison et al., 2007). It behaves viscoelastic material properties when subjected to low-speed tension. But when subjected to high-speed tension, PVB exhibited elastoplastic behavior. Nevertheless, most deformation in the elongated PVB specimens under high strain rates recovered after loading, which indicates that the PVB is still viscoelastic. Since there is no available testing data on the dynamic unloading behavior of PVB, it is therefore not feasible to formulate the material model of PVB under dynamic loading. As the primary concern of laminated glass under debris impact loading in this study is the anti-penetration performance, the unloading behavior is less important; an elasto-plastic material model is utilized, which follows the authors' laboratory testing data on PVB under dynamic tension.

Yield stress, failure stress, initial Young's modulus and plastic modulus of PVB at different strain rates are collected from experiment data. The best-fitted equations with respect to strain rates for these quantities are derived as:

- $\quad$ For yield stress (in MPa):

$$
\sigma_{\text {yield }}=2.167(\dot{\varepsilon})^{0.399}
$$

- For initial Young's modulus (in MPa):

$$
E_{\text {initial }}=30.591(\dot{\varepsilon})^{0.271}
$$

- For failure stress (in MPa):

$$
\sigma_{\text {failure }}=27.689(\dot{\varepsilon})^{0.040}
$$

where, $\dot{\varepsilon}$ is the strain rate.

The density of PVB is $1100 \mathrm{~kg} / \mathrm{m}^{3}$ and the Poisson's ratio is 0.495 . The plastic modulus measured in the experiments is averaged and $11 \mathrm{MPa}$ is taken in this study. The fitted stress-strain relations are programmed and implemented into LS-DYNA code to conduct the numerical simulations.

\section{Timber}

The timber projectile is generated with $100 \mathrm{~mm}$ by 50 $\mathrm{mm}$ frontal cross-section area. In practice, hard pine is most frequently used as projectile. Since minimal timber deformation is observed in the previous test and the study focuses on the performance of glass windows, a linear elastic material model is used for timber projectile with a density of $820 \mathrm{~kg} / \mathrm{m}^{3}$ and Young's modulus as 20
$\mathrm{GPa}$. The velocity of timber projectile is launched from 10 to $40 \mathrm{~m} / \mathrm{s}$ with an increment of $5 \mathrm{~m} / \mathrm{s}$.

\section{Window Frame}

No yielding or plastic deformation was previously observed to the steel or aluminium window frame in the laboratory test, the window frame is therefore omitted and represented as fixed boundary. To account for the influence of bearing, a $20 \mathrm{~mm}$ thick and $50 \mathrm{~mm}$ wide supporting strips with Young's modulus varying from 200 to $100 \mathrm{GPa}, 20$ and $2 \mathrm{GPa}$ is modelled.

\section{Analysis}

\section{Model Calibration}

The generated numerical model of laminated glass windows is calibrated with a previous laboratory debris impact test by (Zhang et al., 2012). A close match is found between the numerical model and the laboratory test results and observations. More details can be found in reference (Zhang and Hao, 2011; Zhang et al., 2013a).

\section{Results}

To examine the influence of bearing support stiffness, the singly laminated glass windows (comprising of two glass panes laminating a single PVB interlayer) is numerically modelled. Two window dimensions, i.e., $2000 \times 1100 \mathrm{~mm}$ and $1100 \times 600 \mathrm{~mm}$ are considered. The standard $7.52 \mathrm{~mm}$ laminated glass is taken into account (two $3 \mathrm{~mm}$ glass panes and a middle $1.52 \mathrm{~mm}$ PVB interlayer). Then, two $3 \mathrm{~mm}$ glass pane with a $3.02 \mathrm{~mm}$ PVB interlayer and two $6 \mathrm{~mm}$ glass pane with $1.52 \mathrm{~mm}$ interlayer are also modelled to check the influence of interlayer and glass pane thicknesses on the overall impact response. The penetration status of the laminated glass windows is examined and the central panel deflection is also used to quantify the performance of the examined glass windows. Finally, in order to study the effectiveness of multiple glass/interlayer solutions in improving the expected window impact resistance, the same dimension of glass windows is further modelled, but with different combinations of glass panes and interlayer thickness. The detailed results are presented in the following sections.

\section{Singly Laminated Glass Window}

\section{Window Penetration State}

Tables 1-4 show the penetration states of the $2000 \times 1100 \mathrm{~mm}$ with different stiffnesses of the supporting frame, under various projectile velocities. The glass pane is fully clamped by the supporting frame. The Young's modulus of the supports varies from a maximum of $200 \mathrm{GPa}$ and down to 100, 20 and $2 \mathrm{GPa}$. 
Table 1: Analysis of penetration states for a $7.52 \mathrm{~mm}$ thick laminated glass section $(3 / 1.52 / 3 \mathrm{~mm})-$ size A $(2000 \times 1100 \mathrm{~mm})$. Key: $\mathrm{X}=$ no penetration; $\mathrm{Y}=$ penetration occurred

\begin{tabular}{|c|c|c|c|c|}
\hline \multirow[b]{2}{*}{ Velocity $(\mathrm{m} / \mathrm{s})$} & \multicolumn{4}{|c|}{ Young's modulus of supporting frame (GPa) } \\
\hline & 2 & 20 & 100 & 200 \\
\hline 10 & $\mathrm{X}$ & $\mathrm{X}$ & $\mathrm{X}$ & $\mathrm{X}$ \\
\hline 15 & $\mathrm{X}$ & $\mathrm{X}$ & $\mathrm{X}$ & $\mathrm{X}$ \\
\hline 20 & $\mathrm{Y}$ & $\mathrm{Y}$ & $\mathrm{Y}$ & $\mathrm{Y}$ \\
\hline 25 & $\mathrm{Y}$ & $\mathrm{Y}$ & $\mathrm{Y}$ & $\mathrm{Y}$ \\
\hline 30 & $\mathrm{Y}$ & $\mathrm{Y}$ & $\mathrm{Y}$ & $\mathrm{Y}$ \\
\hline 35 & $\mathrm{Y}$ & $\mathrm{Y}$ & $\mathrm{Y}$ & $\mathrm{Y}$ \\
\hline 40 & $\mathrm{Y}$ & $\mathrm{Y}$ & $\mathrm{Y}$ & $\mathrm{Y}$ \\
\hline
\end{tabular}

Table 2: Analysis of penetration states for a $9.04 \mathrm{~mm}$ thick laminated glass section $(3 / 3.04 / 3 \mathrm{~mm})-$ size A $(2000 \times 1100 \mathrm{~mm})$. Key: $\mathrm{X}=$ no penetration; $\mathrm{Y}=$ penetration occurred

\begin{tabular}{lllll}
\hline & \multicolumn{2}{c}{ Young's modulus of supporting frame $(\mathrm{GPa})$} & & \\
Velocity $(\mathrm{m} / \mathrm{s})$ & - & 20 & $\mathrm{X}$ & 200 \\
\hline 10 & 2 & $\mathrm{X}$ & $\mathrm{X}$ & $\mathrm{X}$ \\
15 & $\mathrm{X}$ & $\mathrm{X}$ & $\mathrm{X}$ & $\mathrm{X}$ \\
20 & $\mathrm{X}$ & $\mathrm{X}$ & $\mathrm{Y}$ & $\mathrm{Y}$ \\
25 & $\mathrm{X}$ & $\mathrm{Y}$ & $\mathrm{Y}$ & $\mathrm{Y}$ \\
30 & $\mathrm{Y}$ & $\mathrm{Y}$ & $\mathrm{Y}$ & $\mathrm{Y}$ \\
35 & $\mathrm{Y}$ & $\mathrm{Y}$ & $\mathrm{Y}$ & $\mathrm{Y}$ \\
40 & $\mathrm{Y}$ & $\mathrm{Y}$ & & \\
\hline
\end{tabular}

Table 3: Analysis of penetration states for a $13.52 \mathrm{~mm}$ thick laminated glass section $(6 / 1.52 / 6 \mathrm{~mm})-$ size A $(2000 \times 1100 \mathrm{~mm})$. Key: $\mathrm{X}=$ no penetration; $\mathrm{Y}=$ penetration occurred Young's modulus of supporting frame $(\mathrm{GPa})$

\begin{tabular}{lllll} 
Velocity $(\mathrm{m} / \mathrm{s})$ & 2 & 20 & 100 & \\
\hline 10 & $\mathrm{X}$ & $\mathrm{X}$ & $\mathrm{X}$ & $\mathrm{X}$ \\
15 & $\mathrm{X}$ & $\mathrm{X}$ & $\mathrm{X}$ & $\mathrm{X}$ \\
20 & $\mathrm{X}$ & $\mathrm{X}$ & $\mathrm{Y}$ & \\
25 & $\mathrm{Y}$ & $\mathrm{Y}$ & $\mathrm{Y}$ & $\mathrm{Y}$ \\
30 & $\mathrm{Y}$ & $\mathrm{Y}$ & $\mathrm{Y}$ & $\mathrm{Y}$ \\
35 & $\mathrm{Y}$ & $\mathrm{Y}$ & $\mathrm{Y}$ & $\mathrm{Y}$ \\
40 & $\mathrm{Y}$ & $\mathrm{Y}$ & & \\
\hline
\end{tabular}

Table 4: Analysis of penetration states for a $15.04 \mathrm{~mm}$ thick laminated glass section $(6 / 3.04 / 6 \mathrm{~mm})-$ size A (2000×1100 mm). Key: $\mathrm{X}=$ no penetration; $\mathrm{Y}=$ penetration occurred Young's modulus of supporting frame (GPa)

\begin{tabular}{lllll} 
Velocity $(\mathrm{m} / \mathrm{s})$ & 2 & 20 & 100 & 200 \\
\hline 10 & $\mathrm{X}$ & $\mathrm{X}$ & $\mathrm{X}$ & $\mathrm{X}$ \\
15 & $\mathrm{X}$ & $\mathrm{X}$ & $\mathrm{X}$ & $\mathrm{X}$ \\
20 & $\mathrm{X}$ & $\mathrm{X}$ & $\mathrm{X}$ & $\mathrm{X}$ \\
25 & $\mathrm{X}$ & $\mathrm{Y}$ & $\mathrm{Y}$ & $\mathrm{Y}$ \\
30 & $\mathrm{Y}$ & $\mathrm{Y}$ & $\mathrm{Y}$ & $\mathrm{Y}$ \\
35 & $\mathrm{Y}$ & $\mathrm{Y}$ & $\mathrm{Y}$ & $\mathrm{Y}$ \\
40 & $\mathrm{Y}$ & $\mathrm{Y}$ & & \\
\hline
\end{tabular}

From Table 1 it can be observed that changing supporting stiffness does not lead to any improvement to the penetration resistance of the laminated glass windows against timber debris impact. For the $2000 \times 1100 \mathrm{~mm}$ windows, all the standard $7.52 \mathrm{~mm}$ laminated glass panes are penetrated under $15 \mathrm{~m} / \mathrm{s}$ debris impact. When increasing PVB interlayer thickness from 1.52 to $3.04 \mathrm{~mm}$ (Table 2), the penetration resistant performance is apparently improved as the penetration threshold velocity increased to $25 \mathrm{~m} / \mathrm{s}$. Similarly, using a 
thicker $6 \mathrm{~mm}$ glass pane to replace the standard $3 \mathrm{~mm}$ annealed also improves the penetration resistance of the laminated glass pane in a manner similar to using thicker PVB interlayer. This is because a thicker glass pane provides more inertia resistance against dynamic impact loading, while increasing PVB interlayer thickness could directly improve the anti-penetration resistance of the laminated sheet. Nevertheless, no difference could be observed to any group of the specimens as a result of different support stiffness. For the size A $(2000 \times 1100 \mathrm{~mm}$ glass window $)$, either standard $7.52 \mathrm{~mm}$ or thickened 9.04 and $13.52 \mathrm{~mm}$ laminated glass panes all exhibit the same penetration threshold against timber debris impact. Only when a much thicker laminated pane is employed (with $6 \mathrm{~mm}$ annealed glass and $3.04 \mathrm{~mm}$ PVB interlayer), the windows with $2 \mathrm{GPa}$ soft support exhibits slightly better impact resistance performance as it manages to hold $25 \mathrm{~m} / \mathrm{s}$ timber debris impact when the other all fail with stiffer supports (Table 4).

When the smaller windows (size B, $1000 \times 600 \mathrm{~mm}$ ) are subjected to debris impact, generally lower resistance can be found for the windows because there are much less inertia resistance and less material to dissipate the impact energy (the same $4 \mathrm{~kg}$ timber projectile and the same impact velocities). As shown in Table 5, for a standard $7.52 \mathrm{~mm}$ laminated glass, when it is fully clamped by $200 \mathrm{GPa}$ steel frame, it is penetrated under $15 \mathrm{~m} / \mathrm{s}$ debris impact. However, the influence of boundary condition becomes prominent. As the Young's modulus of the supporting frame material reduces to 20 and $2 \mathrm{GPa}$, the laminated glass pane is found to survive $15 \mathrm{~m} / \mathrm{s}$ impact. Being similar to the larger $2000 \times 1100 \mathrm{~mm}$ window cases, using a thicker $3.04 \mathrm{~mm}$ PVB interlayer effectively helps to increase the penetration resistance, as can be seen in Table 6 that all the laminated panes survive $20 \mathrm{~m} / \mathrm{s}$ impact. It reflects that increasing PVB interlayer thickness could very effectively improve the debris penetration resistance against timber projectile. As shown in Table 7, increasing glass pane thickness from 3 to $6 \mathrm{~mm}$ could also improve window penetration resistance, but not as effective as increasing interlayer thickness, while to be noticed that when using a thicker glass or a thicker interlayer (Table 8) the influence of support stiffness become negligible and when a thicker glass pane and a thicker PVB interlayer are used simultaneously, the penetration resistance of the laminated glass pane is further improved and a softer support appears to help improve the performance as evidenced that the panel is penetrated when $200 \mathrm{GPa}$ steel support is used.

\section{Glass Pane Cracking Pattern}

Erosion is used to model the crack initiation and propagation of the glass panes. As the timber projectile impacts the frontal surface of the glass pane, crack begins to initiate as the resulted tensile stress becomes larger than glass strength. Crack quickly develops in a circular pattern as the impact-induced stress wave spreads radially.

Table 5: Analysis of penetration states for a $7.52 \mathrm{~mm}$ thick laminated glass section (3/1.52/3 mm) - size B (1000×600 mm). Key: $\mathrm{X}$ $=$ no penetration; $\mathrm{Y}=$ penetration occurred

\begin{tabular}{|c|c|c|c|c|}
\hline \multirow[b]{2}{*}{ Velocity $(\mathrm{m} / \mathrm{s})$} & \multicolumn{4}{|c|}{ Young's modulus of supporting frame (GPa) } \\
\hline & 2 & 20 & 100 & 200 \\
\hline 10 & $\mathrm{X}$ & $\mathrm{X}$ & $\mathrm{X}$ & $\mathrm{X}$ \\
\hline 15 & $\mathrm{X}$ & $\mathrm{X}$ & $\mathrm{Y}$ & $\mathrm{Y}$ \\
\hline 20 & $\mathrm{Y}$ & $\mathrm{Y}$ & $\mathrm{Y}$ & $\mathrm{Y}$ \\
\hline 25 & $\mathrm{Y}$ & $\mathrm{Y}$ & $\mathrm{Y}$ & $\mathrm{Y}$ \\
\hline 30 & $\mathrm{Y}$ & $\mathrm{Y}$ & $\mathrm{Y}$ & $\mathrm{Y}$ \\
\hline 35 & $\mathrm{Y}$ & $\mathrm{Y}$ & $\mathrm{Y}$ & $\mathrm{Y}$ \\
\hline 40 & Y & $\mathrm{Y}$ & Y & $\mathrm{Y}$ \\
\hline
\end{tabular}

Table 6: Analysis of penetration states for a $9.04 \mathrm{~mm}$ thick laminated glass section (3/3.04/3 mm) - size B (1000×600 mm). Key: X = no penetration; $\mathrm{Y}=$ penetration occurred

\begin{tabular}{|c|c|c|c|c|}
\hline \multirow[b]{2}{*}{ Velocity $(\mathrm{m} / \mathrm{s})$} & \multicolumn{4}{|c|}{ Young's modulus of supporting frame (GPa) } \\
\hline & 2 & 20 & 100 & 200 \\
\hline 10 & $\mathrm{X}$ & $\mathrm{X}$ & $X$ & $X$ \\
\hline 15 & $\mathrm{X}$ & $X$ & $\mathrm{X}$ & $X$ \\
\hline 20 & $\mathrm{X}$ & $\mathrm{X}$ & $\mathrm{X}$ & $X$ \\
\hline 25 & $\mathrm{Y}$ & $\mathrm{Y}$ & $\mathrm{Y}$ & $\mathrm{Y}$ \\
\hline 30 & $\mathrm{Y}$ & $\mathrm{Y}$ & $\mathrm{Y}$ & $\mathrm{Y}$ \\
\hline 35 & $\mathrm{Y}$ & $\mathrm{Y}$ & $\mathrm{Y}$ & $\mathrm{Y}$ \\
\hline 40 & $\mathrm{Y}$ & $\mathrm{Y}$ & $\mathrm{Y}$ & $\mathrm{Y}$ \\
\hline
\end{tabular}


Xihong Zhang et al. / International Journal of Structural Glass and Advanced Materials Research 2020, Volume 4: 209.224 DOI: 10.3844/sgamrsp.2020.209.224

Table 7: Analysis of penetration states for $13.52 \mathrm{~mm}$ thick laminated glass section $(6 / 1.52 / 6 \mathrm{~mm})-\operatorname{size} \mathrm{B}(1000 \times 600 \mathrm{~mm})$. Key: X = no penetration; $\mathrm{Y}=$ penetration occurred

\begin{tabular}{lllll}
\hline & Young's modulus of supporting frame (GPa) & & \\
Velocity (m/s) & CG & 20 & 100 & X \\
10 & X & X & X & X \\
15 & X & X & Y & Y \\
20 & Y & Y & Y & Y \\
25 & Y & Y & Y & Y \\
30 & Y & Y & Y & Y \\
35 & Y & Y & Y & \\
40 & Y & Y & & \\
\hline
\end{tabular}

Table 8: Analysis of penetration states for $15.04 \mathrm{~mm}$ thick laminated glass section (6/3.04/6 mm) - panel B (1000×600 mm). Key: X $=$ no penetration; $\mathrm{Y}=$ penetration occurred

\begin{tabular}{|c|c|c|c|c|}
\hline \multirow[b]{2}{*}{ Velocity $(\mathrm{m} / \mathrm{s})$} & \multicolumn{4}{|c|}{ Young's modulus of supporting frame (GPa) } \\
\hline & 2 & 20 & 100 & 200 \\
\hline 10 & $\bar{X}$ & $\mathrm{X}$ & $\mathrm{X}$ & $\mathrm{X}$ \\
\hline 15 & X & $\mathrm{X}$ & $\mathrm{X}$ & $\mathrm{X}$ \\
\hline 20 & $\mathrm{X}$ & $\mathrm{X}$ & $\mathrm{X}$ & $\mathrm{X}$ \\
\hline 25 & $\mathrm{X}$ & $\mathrm{X}$ & $\mathrm{X}$ & $\mathrm{Y}$ \\
\hline 30 & $\mathrm{Y}$ & Y & $\mathrm{Y}$ & $\mathrm{Y}$ \\
\hline 35 & Y & $\mathrm{Y}$ & $\mathrm{Y}$ & $\mathrm{Y}$ \\
\hline 40 & $\mathrm{Y}$ & $\mathrm{Y}$ & $\mathrm{Y}$ & $\mathrm{Y}$ \\
\hline
\end{tabular}

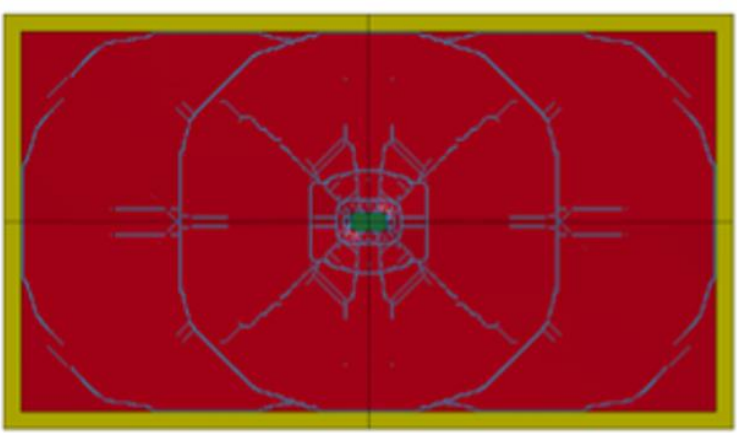

20 GPa support

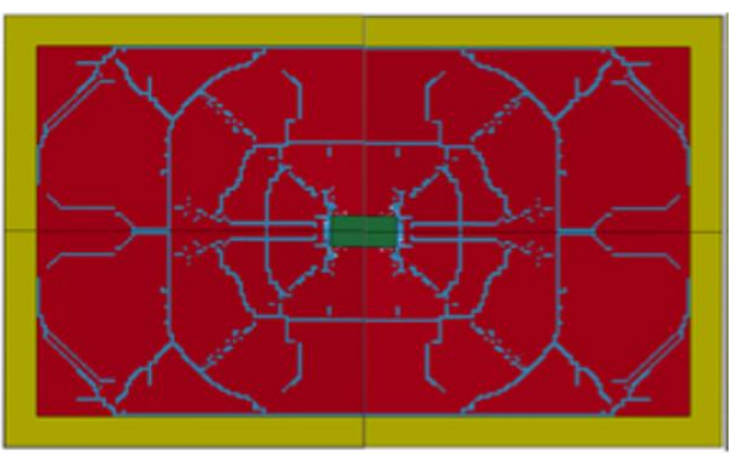

20 GPa support

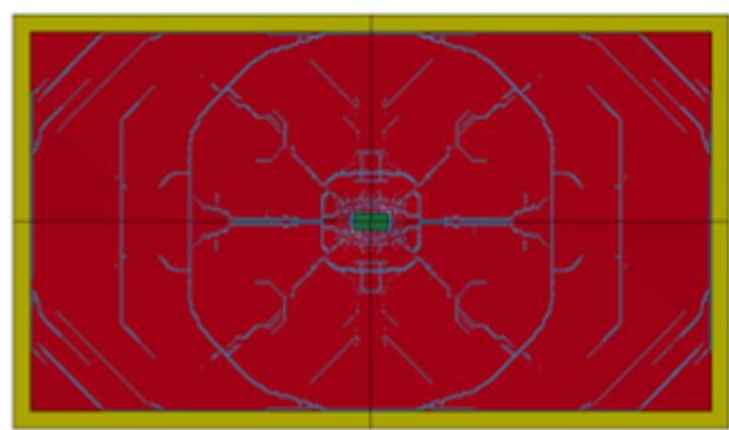

200 GPa support

(a)

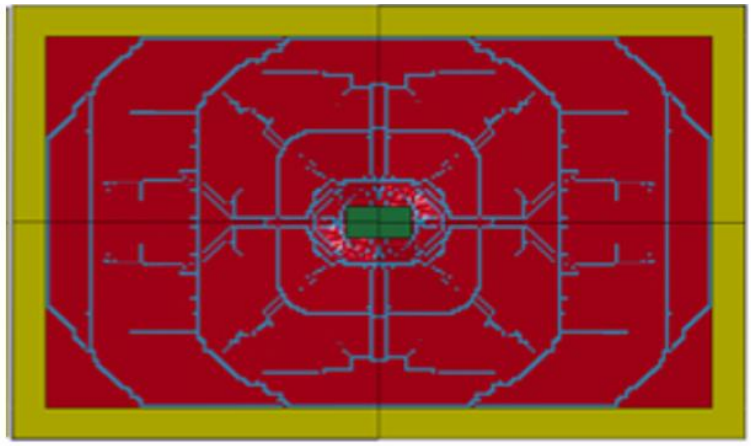

$200 \mathrm{GPa}$ support

(b)

Fig. 4: Glass pane cracking patterns for (a) size A $(2000 \times 1100 \mathrm{~mm}$ windows $)$ or (b) size B (1000×600 mm windows) 
Figure 4 show the glass pane cracking patterns of the $2000 \times 1100 \mathrm{~mm}$ (Fig. 4a) and $1100 \times 600 \mathrm{~mm}$ (Fig. 4b) windows respectively, under a given $15 \mathrm{~m} / \mathrm{s}$ impact. Two different stiffness values $(20$ and $200 \mathrm{Gpa}$ ) are taken into account for the supporting frames and used to demonstrate the influence of support stiffness in terms of observed cracking pattern for the glass layers. An apparent difference can be observed in the comparative contour plots od Fig. 4, where the glass pane supported by the stiffer frame experienced more severe cracks in the size A configuration $(2000 \times 1100 \mathrm{~mm}$, Fig. 4a). Similar observations can be derived for the size $B$ panels $(1000 \times 600 \mathrm{~mm}$ windows, Fig. $4 \mathrm{~b})$, which nevertheless is a less pronounced effect. This indicates that the stiffness of the supporting frame could certainly influence the expected damage for the glass panes and thus represents a critical aspect to properly account in design and analysis.

\section{Central Deflection}

The window central deflection time histories for the $2000 \times 1100 \mathrm{~mm}$ laminated glass windows are shown in Fig. 5. The windows are subjected to $15 \mathrm{~m} / \mathrm{s}$ debris impact. When subjected to the timber projectile impact, the central deflection of the laminated glass panel quickly increases as the glass panes break and the PVB interlayer holds the shattered glass shards to deform under the action of the projectile. Since no penetration is formed, the glass pane rebounds.

For the $7.52 \mathrm{~mm}$ laminated glass pane in Fig. 5a, a slight difference can be found on the peak central deflection for the examined panels with different support stiffness, where the smallest deflection is found for the stiffest support. Such an effect and support stiffness influence is more apparent on the rebound response, where the window with the softest support shows the longest free vibration duration. The influence of window support stiffness becomes less apparent, otherwise, when a thicker interlayer is used for the $9.04 \mathrm{~mm}$ laminated glass windows (see the comparative plots in Fig. 5b). A marginal difference in the collected peak deflections can be observed for panels with different supports. Similarly, as shown in Fig. $5 \mathrm{c}$ and $5 \mathrm{~d}$ on the 2000 by $1100 \mathrm{~mm}$ windows with $6 \mathrm{~mm}$ thick annealed glass, the dynamic responses of the windows with supports of different stiffness exhibit different responses. The numerical outcomes further demonstrates that by decreasing the support stiffness, the dynamic response of the laminated glass window could be influenced. Moreover, this suggests that a certain dynamic de-amplification effect could be produced and properly optimized, if the stiffness of the support is designed in detail, by taking into account the natural frequency of the laminated glass pane.

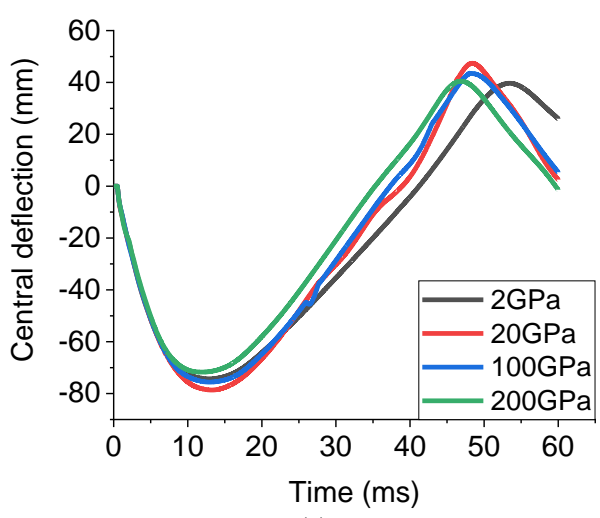

(a)

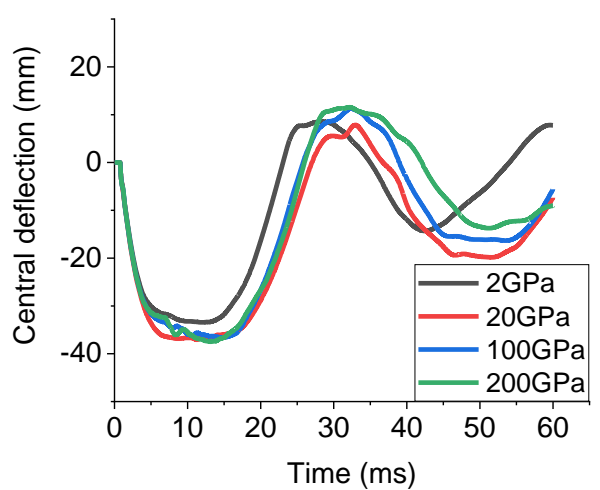

(c)

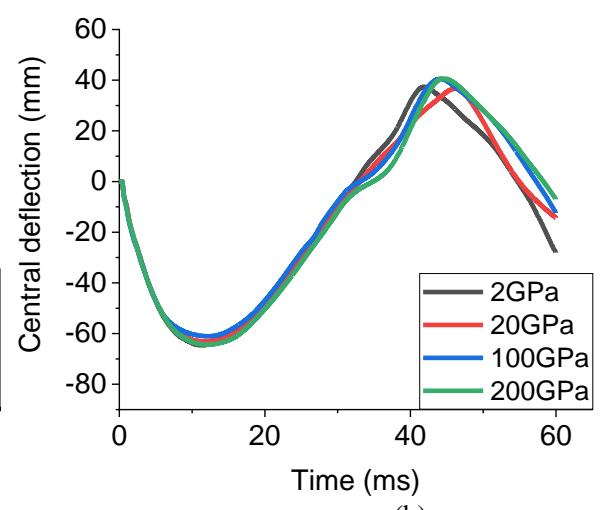

(b)

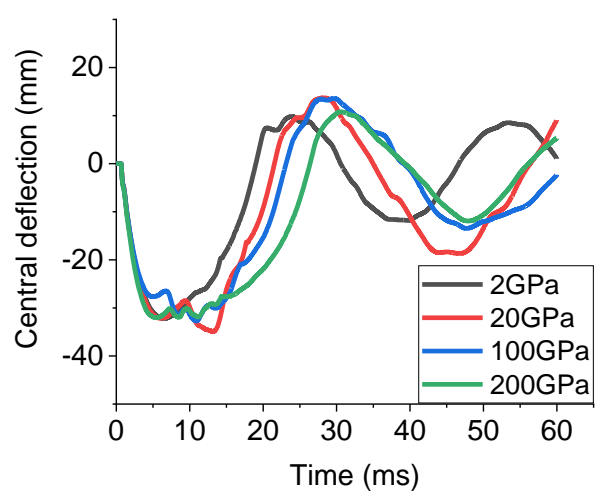

(d)

Fig. 5: Central deflection in time for size A laminated glass windows $(2000 \times 1100 \mathrm{~mm})$ under $15 \mathrm{~m} / \mathrm{s}$ impact. Analysis of results for (a) $3 / 1.52 / 3 \mathrm{~mm}$; (b) $3 / 3.04 / 3 \mathrm{~mm}$; (c) $6 / 1.52 / 6 \mathrm{~mm}$ or (d) $6 / 3.04 / 6 \mathrm{~mm}$ cross sections, as function of the frame stiffness 


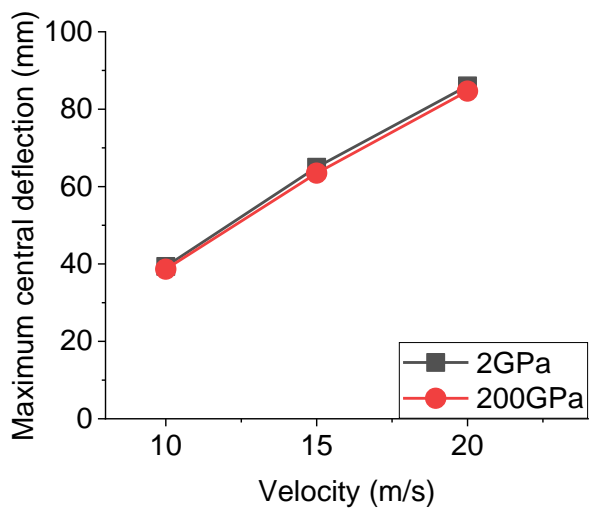

(a)

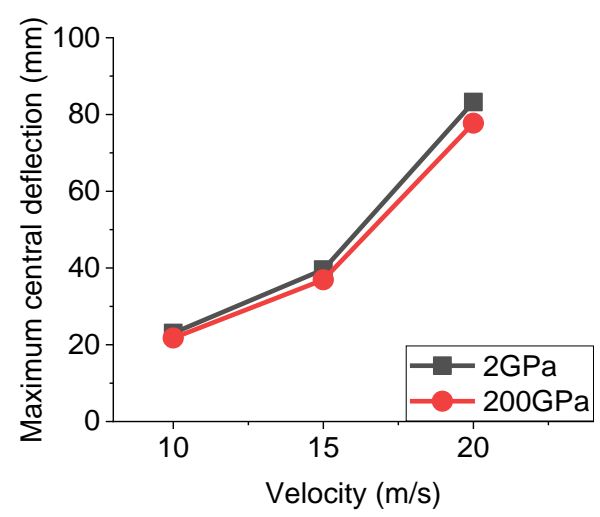

(b)

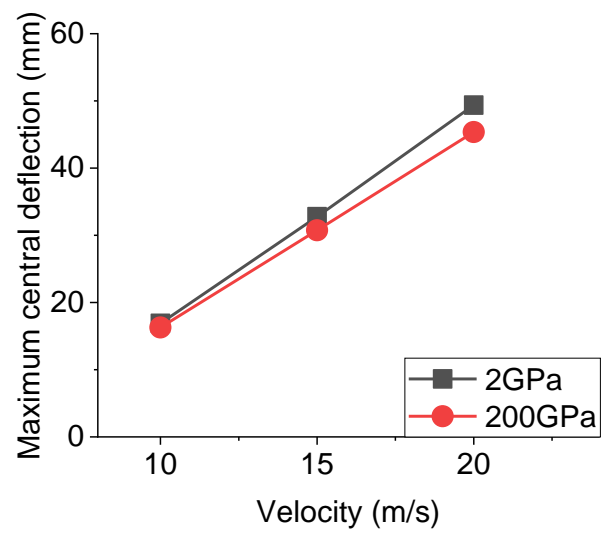

(c)

Fig. 6: Comparative analysis of peak central deflections for laminated glass windows with different support stiffness (size A, $2000 \times 1100 \mathrm{~mm}$ ): (a) $3 / 3.04 / 3 \mathrm{~mm}$; (b) $6 / 1.52 / 6 \mathrm{~mm}$ and (c) $6 / 3.04 / 6 \mathrm{~mm}$

The maximum central deflections for the $2000 \times 1100$ $\mathrm{mm}$ windows with 2 and $200 \mathrm{GPa}$ supports, under different debris impact, are then summarized and compared in Fig. 6, grouped by cross section properties. It can be observed that the windows with softer supports show slightly larger central deflection. For instance, the maximum central deflections of $7.52 \mathrm{~mm}$ laminated glass panes supported using $2 \mathrm{GPa}$ soft frames are calculated in 42,65 and $87 \mathrm{~mm}$ for $10,15,20 \mathrm{~m} / \mathrm{s}$ impacts, respectively. In comparison, when employing a much stiffer steel supporting frame (200 GPa), the maximum central deflections become 39, 61 and $86 \mathrm{~mm}$ respectively. The above comparison show it is not very effective to use a softer window supporting frame to improve its debris impact resistance, while in comparison changing PVB interlayer thickness has much more prominent effect.

\section{Doubly Laminated Glass Window}

To improve penetration resistance, doubly laminated glass panes are examined instead of purely increasing interlayer thickness. This is considering the fact that a very thick PVB interlayer would alter the load path of the composite pane. Instead, an optimized multiple layer composite structures could provide better penetration resistance and the interlayer could also provide more moment resistance. A standard $2000 \times 1100 \mathrm{~mm}$ window is considered and for the doubly laminated glass two cases are examined, i.e., $12.04 \mathrm{~mm}$ pane comprising three $3 \mathrm{~mm}$ thick annealed glass and two $1.52 \mathrm{~mm}$ thick PVB interlayers and $15.04 \mathrm{~mm}$ pane comprising one 6 $\mathrm{mm}$ thick outer annealed glass and two $3 \mathrm{~mm}$ thick glass, together with two $1.52 \mathrm{~mm}$ thick PVB interlayer. Supporting frames of different stiffness are still assessed by using material with various Young's modulus, as also previously described.

\section{Window Penetration State}

Tables 9 and 10 show the window penetration state. It can be observed that employing the doubly laminated glass pane could effectively improve the penetration resistance of the windows. The penetration threshold increases to $30 \mathrm{~m} / \mathrm{s}$ in comparison to $25 \mathrm{~m} / \mathrm{s}$ for the 15.04 $\mathrm{mm}$ singly laminated glass pane. Despite the same glass and interlayer used but by optimizing the layout, better 
penetration resistance can be achieved. Also, similar to the singly laminated glass windows, there appears to be almost no influence from support stiffness to the penetration resistance performance of the doubly laminated glass windows. It is different from the observation for the laminated glass window under blast loading. This is because of different failure modes that, when subjected to blast loading, the doubly laminated glass pane fails due to flexural bending, while when subjected to debris impact, the laminated glass panes have very localized penetration failure where energy concentrates at the impact location.

\section{Glass Pane Cracking Pattern}

Figure 7 shows the glass pane cracking patterns of the doubly laminated glass panes under $25 \mathrm{~m} / \mathrm{s}$ debris impact. It can be observed that the glass panes crack radially indicating flexural deformation of the laminated panes under the impact of the timber projectile. Slightly less severe damages can be found for the pane supported by the softer frame ( $2 \mathrm{GPa}$ material). This is because the boundary motion help to reduce the net deflection of the glass pane, which consequentially reliefs the cracking of the glass panels.

Table 9: Analysis of penetration states for a $12.04 \mathrm{~mm}$ thick laminated glass section $(3 / 1.52 / 3 / 1.52 / 3 \mathrm{~mm})-\operatorname{size} \mathrm{A}(2000 \times 1100$ $\mathrm{mm})$. Key: $X=$ no penetration; $Y=$ penetration occurred

\begin{tabular}{|c|c|c|c|c|}
\hline \multirow[b]{2}{*}{ Velocity $(\mathrm{m} / \mathrm{s})$} & \multicolumn{4}{|c|}{ Young's modulus of supporting frame (GPa) } \\
\hline & 2 & 20 & 100 & 200 \\
\hline 10 & $\mathrm{X}$ & $\mathrm{X}$ & $\mathrm{X}$ & $\mathrm{X}$ \\
\hline 15 & $\mathrm{X}$ & $\mathrm{X}$ & $\mathrm{X}$ & $\mathrm{X}$ \\
\hline 20 & $\mathrm{X}$ & $\mathrm{X}$ & $\mathrm{X}$ & $\mathrm{X}$ \\
\hline 25 & $\mathrm{X}$ & $\mathrm{X}$ & $\mathrm{X}$ & $\mathrm{X}$ \\
\hline 30 & $\mathrm{Y}$ & $\mathrm{Y}$ & $\mathrm{Y}$ & $\mathrm{Y}$ \\
\hline 35 & $\mathrm{Y}$ & $\mathrm{Y}$ & $\mathrm{Y}$ & Y \\
\hline 40 & $\mathrm{Y}$ & $\mathrm{Y}$ & $\mathrm{Y}$ & $\mathrm{Y}$ \\
\hline
\end{tabular}

Table 10: Analysis of penetration states for a $15.04 \mathrm{~mm}$ thick laminated glass section $(6 / 1.52 / 3 / 1.52 / 3 \mathrm{~mm})-\operatorname{size} \mathrm{A}(2000 \times 1100$ $\mathrm{mm})$. Key: $\mathrm{X}=$ no penetration; $\mathrm{Y}=$ penetration occurred

\begin{tabular}{lllll}
\hline & Young's modulus of supporting frame (GPa) & \\
Velocity (m/s) & - & 20 & 100 & X \\
\hline 10 & 2 & X & X \\
15 & X & X & X & X \\
20 & X & X & X & X \\
25 & X & X & Y & Y \\
30 & X & Y & Y & Y \\
35 & Y & Y & Y & Y \\
40 & Y & Y & & \\
\hline
\end{tabular}
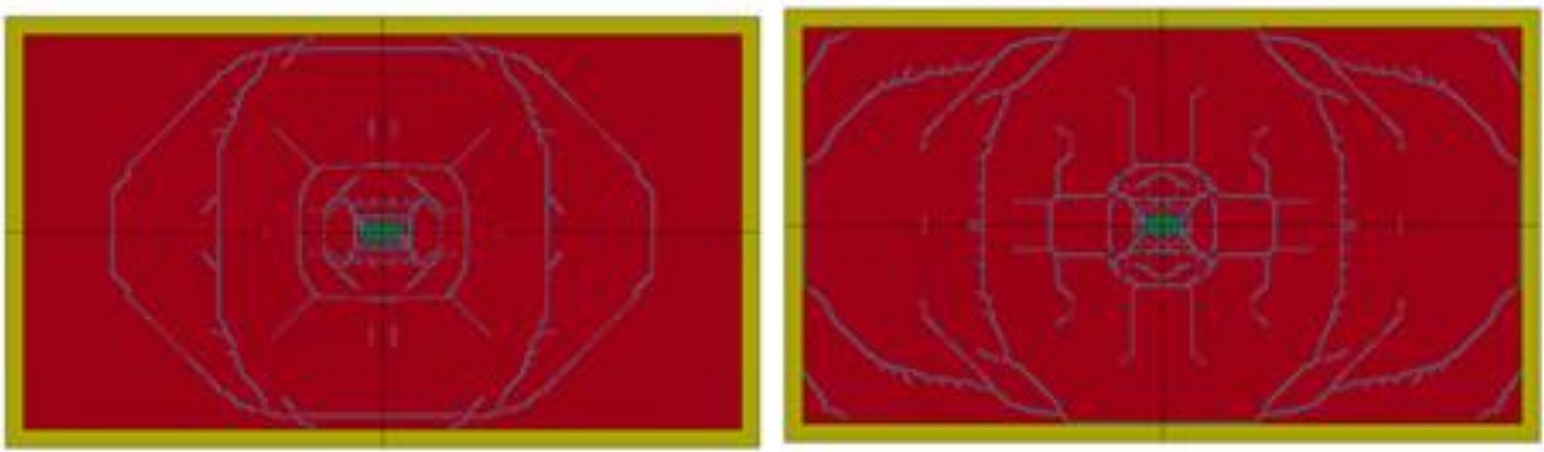

$2 \mathrm{GPa} 200 \mathrm{GPa}$

Fig. 7: Observed cracking pattern for doubly laminated glass windows (size A, 2000×1100 mm) 


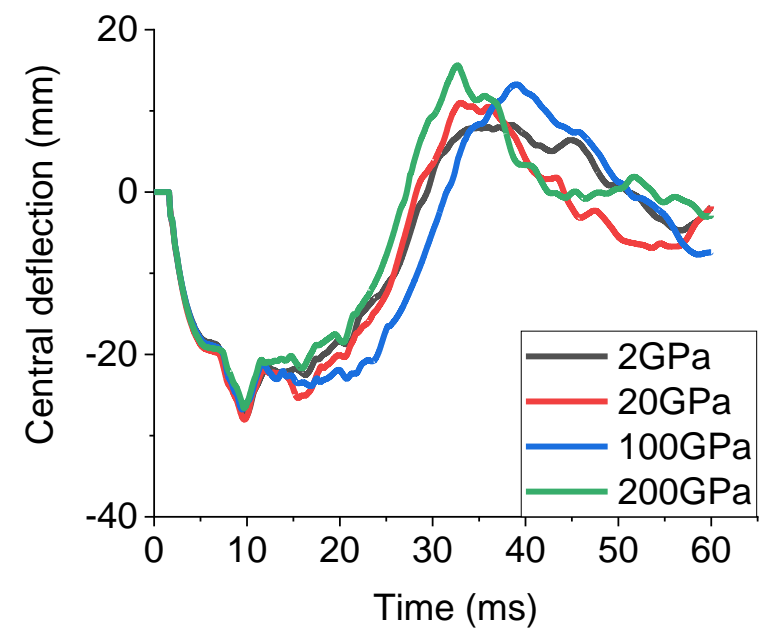

(a)

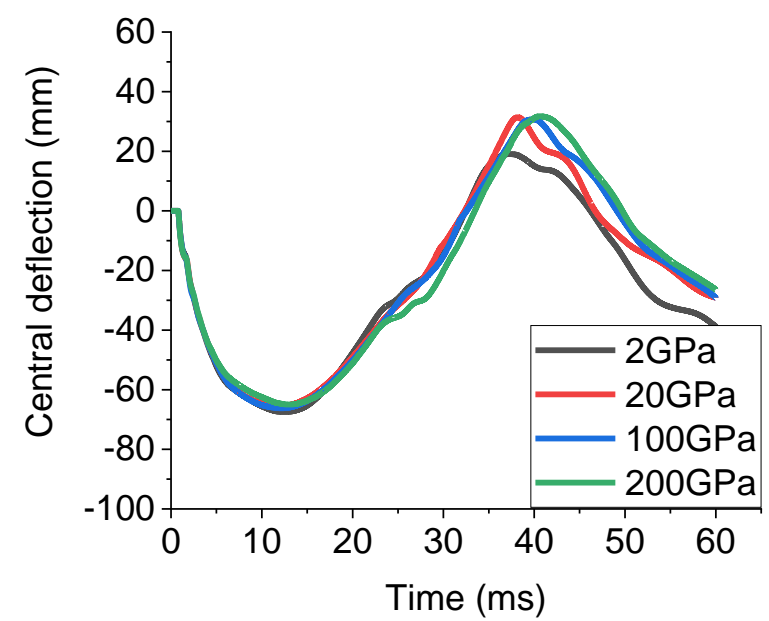

(b)

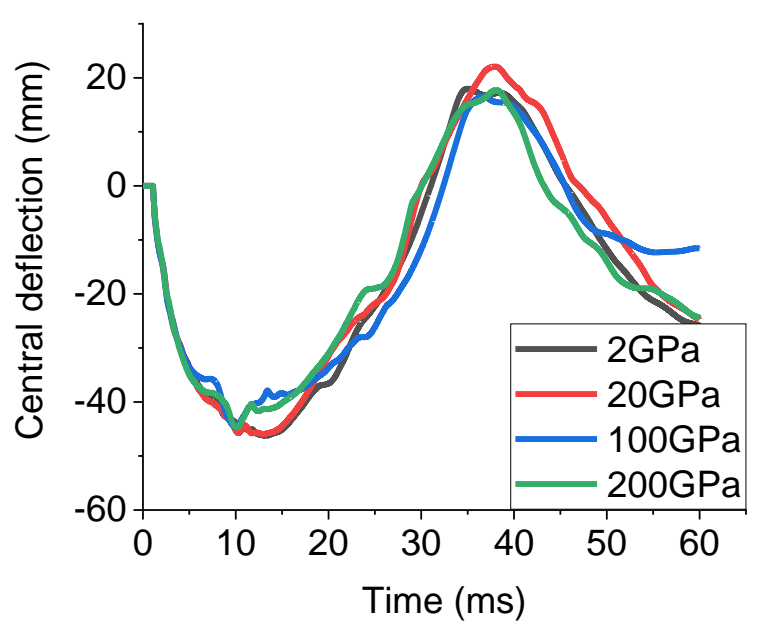

(b)

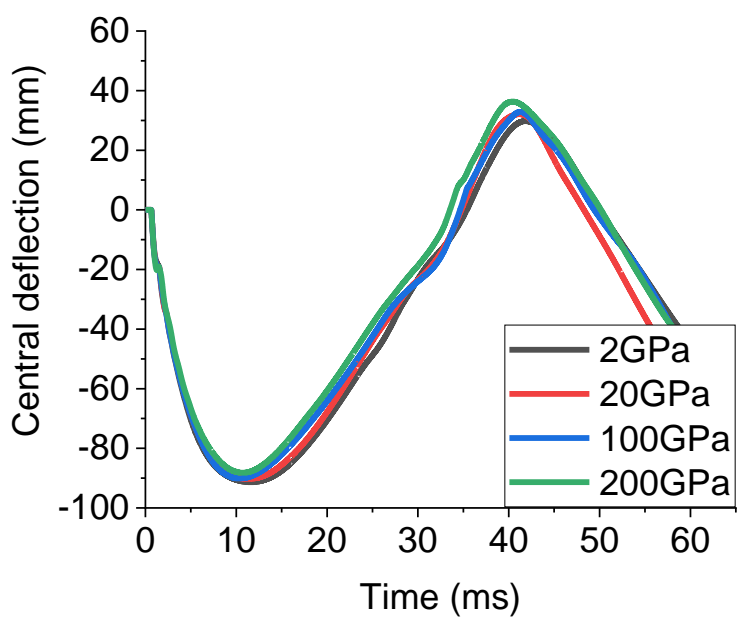

(d)

Fig. 8: Central deflection time histories for $12.04 \mathrm{~mm}$ thick doubly laminated glass windows: (a) 3/1.52/3 mm; (b) 3/3.04/3 mm; (c) $6 / 1.52 / 6 \mathrm{~mm}$ and (d) $6 / 3.04 / 6 \mathrm{~mm}$

\section{Central Deflection}

Figure 8 and 9 show the central deflection time histories for the 12.04 and $15.04 \mathrm{~mm}$ doubly laminated glass windows supported by frames of different stiffness. From Fig. 8 it can be observed that for the $12.04 \mathrm{~mm}$ doubly laminated glass panes the central deflections under forced vibration phases are very similar. When the panels rebound, more noticeable differences can be observed that the windows with softer supports have longer free vibration periods indicating the boundary condition influence the stiffness of the system. A similar observation can be found on the $15.04 \mathrm{~mm}$ doubly laminated glass windows.

This proves the authors' previous finding that a pinned boundary could alter the natural frequency of the window system and therefore influence the $t n / T$ ratio (where $t n$ is the loading duration and $T$ is the natural period of the window) which could lead to the de-amplification effect of the dynamic response of laminated glass panels. However, it is less prominent to the forced vibration phase of laminated glass pane under windborne debris impact, because the failure of the window is interlayer penetration and the influence of boundary condition to the dynamic response during timber projectile forced window panel vibration is minor.

The maximum window central deflections for the two doubly laminated glass windows supported by the softest and stiffest frames are summarized and shown in Fig. 10. It can be observed that minor differences in the maximum central deflections can be found which indicates that supporting condition does not have much influence to the dynamic response of the doubly laminated glass windows. 


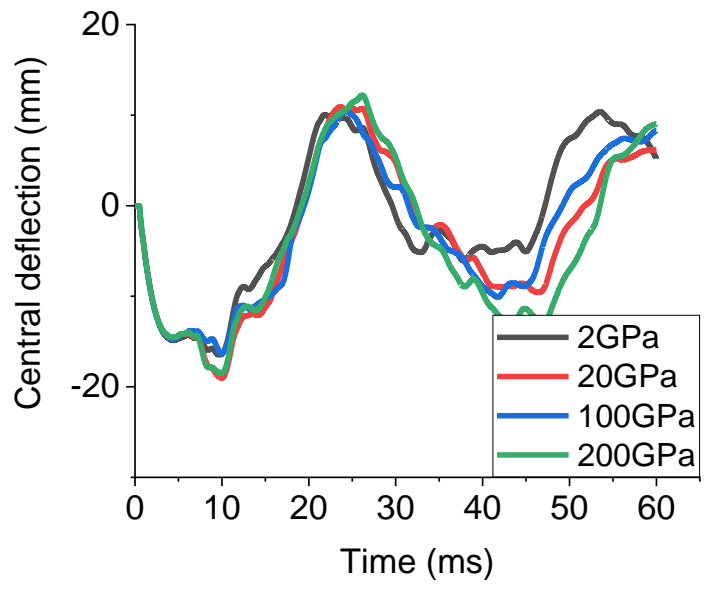

(a)

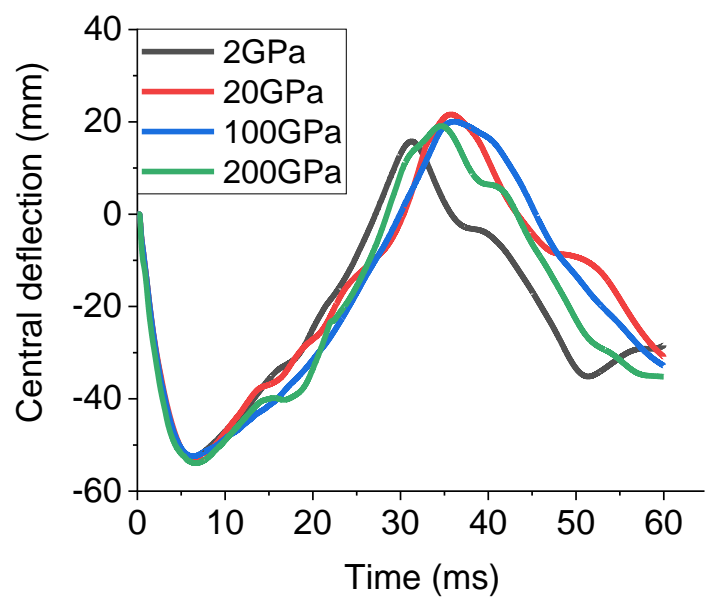

(c)

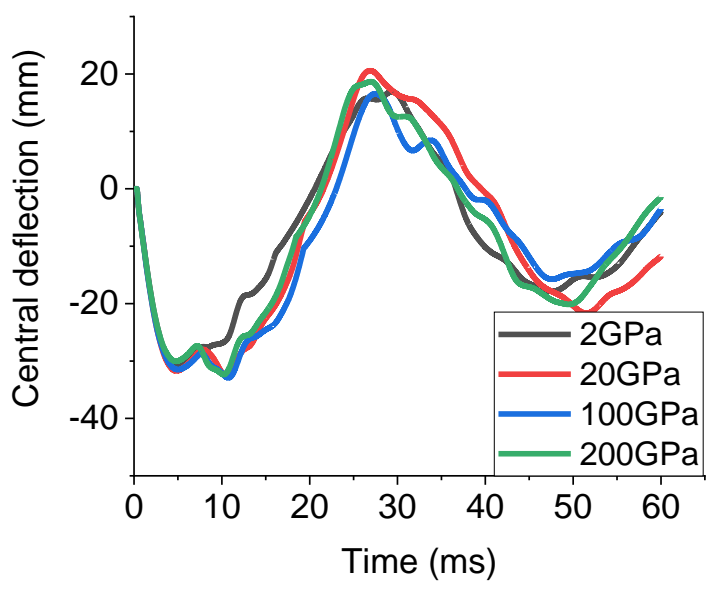

(b)

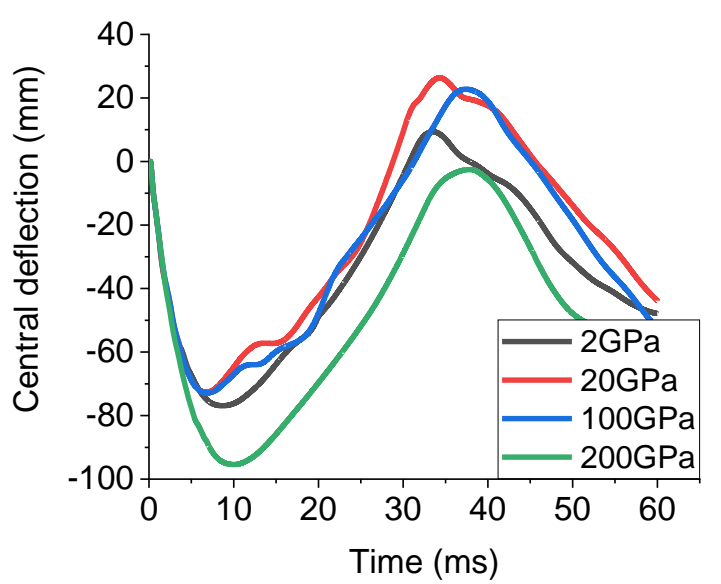

(d)

Fig. 9: Central deflection time histories for $15.04 \mathrm{~mm}$ thick doubly laminated glass windows: (a) $3 / 1.52 / 3 \mathrm{~mm}$; (b) $3 / 3.04 / 3 \mathrm{~mm}$; (c) $6 / 1.52 / 6 \mathrm{~mm}$ and (d) 6/3.04/6 mm

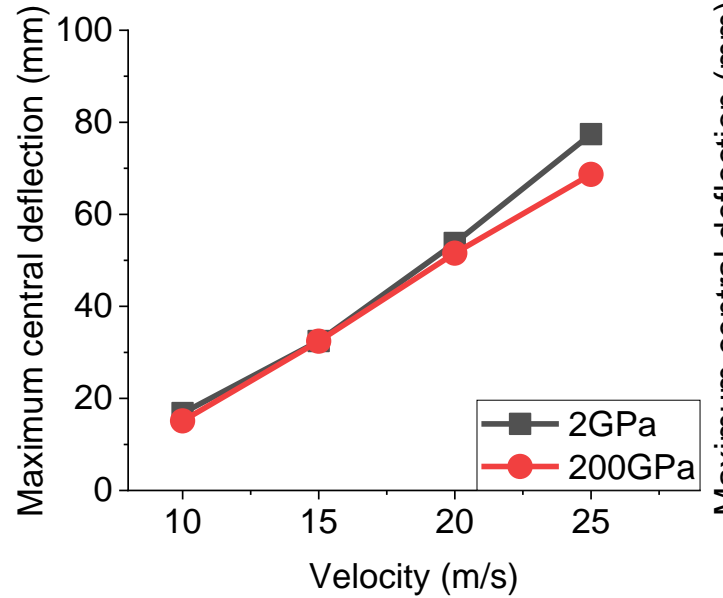

(a)

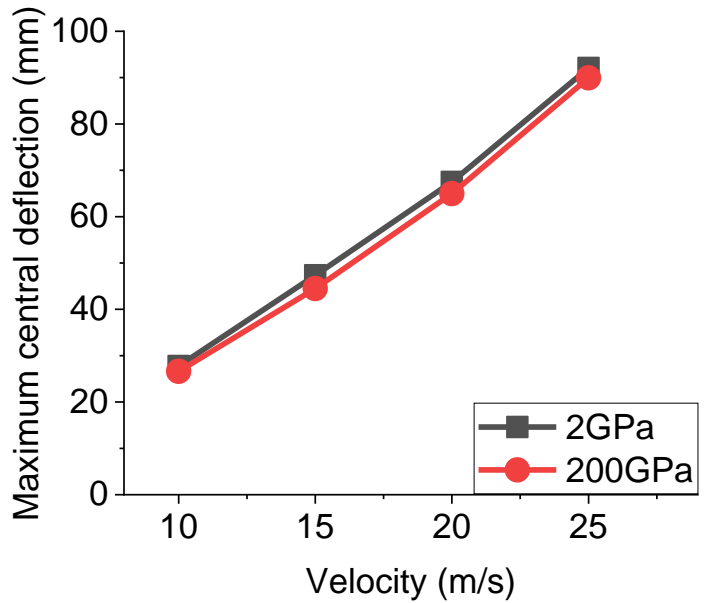

(b)

Fig. 10: Maximum central deflections for size B $(2000 \times 1100 \mathrm{~mm})$ doubly laminated glass windows: (a) $3 / 1.52 / 3 / 1.52 / 3 \mathrm{~mm}$ and (b) $6 / 1.52 / 3 / 1.52 / 3 \mathrm{~mm}$ 


\section{Comparison of Singly and Doubly Laminated Glass Windows}

As mentioned above, laminated glass panes with the same total glass and PVB thickness but different layout, i.e., singly laminated using thicker panes, or doubly laminated using multiple thinner panes, could provide different dynamic responses under windborne debris impact conditions. In this section, the performances of the singly and doubly laminated $15.04 \mathrm{~mm}$ glass windows are compared to demonstrate the effectiveness of layout optimization.

\section{Window Penetration State}

Table 11 compares the penetration states of the singly and doubly laminated glass windows. As can be seen that the doubly laminated glass gets penetrated at $30 \mathrm{~m} / \mathrm{s}$ impact velocity, while the singly laminated glass is penetrated at $25 \mathrm{~m} / \mathrm{s}$ impact velocity. It is apparent that by optimizing the layout of the glass and interlayer, the debris impact resistance can be effectively improved.

\section{Glass Pane Cracking Pattern}

Figure 11 compares the glass pane cracking patterns under $15 \mathrm{~m} / \mathrm{s}$ impact velocity. As can be observed, slightly more severed glass damages are developed on the singly laminated glass windows. It should be noted again here that the two glass windows have the exact total glass pane thickness and interlayer thickness, which means theoretically speaking similar amounts of energy could be consumed. However, as discussed above for debris impact, the failure in the laminated glass pane is very concentrated in the impact region and optimized local impact resistance could be achieved if designed properly.

Table 11: Comparison of penetration states of singly and doubly laminated windows. Key: $\mathrm{X}=$ no penetration; $\mathrm{Y}=$ penetration occurred

\begin{tabular}{lll}
\hline Velocity $(\mathrm{m} / \mathrm{s})$ & Singly laminated $(6 / 3.04 / 6)$ & Doubly laminated $(6 / 1.52 / 3 / 1.52 / 3)$ \\
\hline 10 & $\mathrm{X}$ & $\mathrm{X}$ \\
15 & $\mathrm{X}$ & $\mathrm{X}$ \\
20 & $\mathrm{X}$ & $\mathrm{X}$ \\
25 & $\mathrm{Y}$ & $\mathrm{X}$ \\
30 & $\mathrm{Y}$ & $\mathrm{Y}$ \\
35 & $\mathrm{Y}$ & $\mathrm{Y}$ \\
40 & $\mathrm{Y}$ & $\mathrm{Y}$ \\
\hline
\end{tabular}

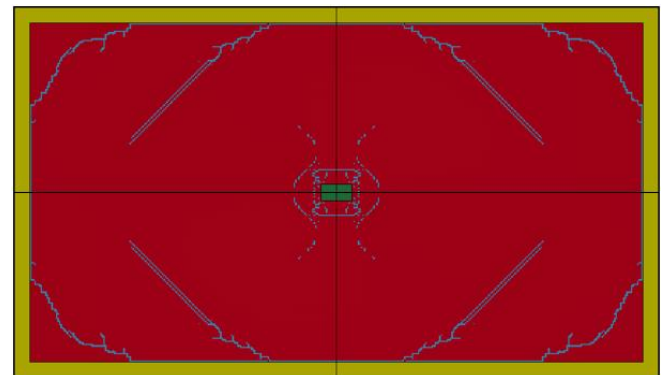

(a)

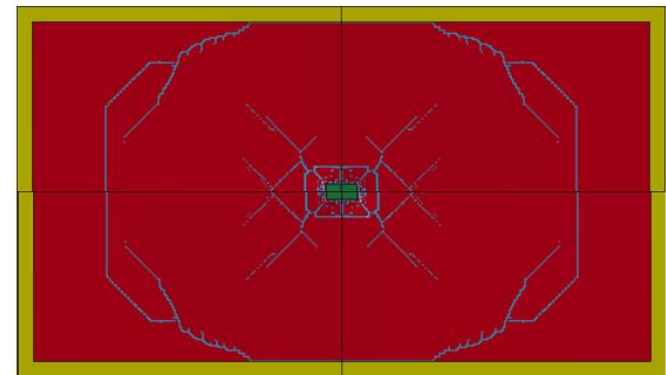

(b)

Fig. 11: Comparison of glass cracking patterns between (a) singly and (b) doubly laminated glass panels

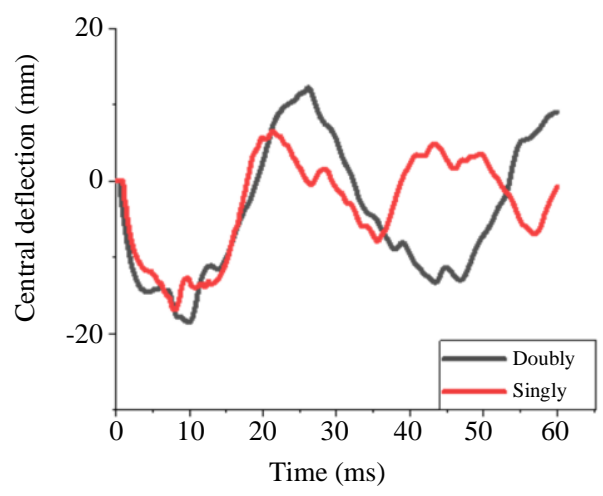

(a)

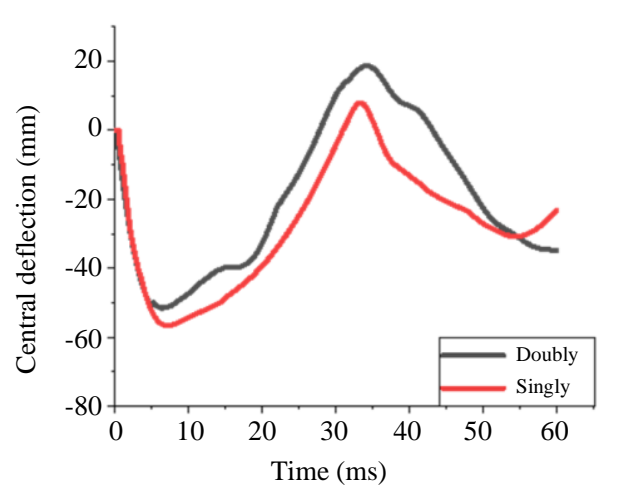

(b)

Fig. 12: Comparison of central deflection time histories for singly and doubly laminated glass windows: (a) $10 \mathrm{~m} / \mathrm{s}$ or (b) $20 \mathrm{~m} / \mathrm{s}$ 


\section{Central Deflection Time Histories}

Figure 12 compares the window central deflection time histories of the singly and doubly laminated glass panels. When subjected to relatively low-velocity impact $(10 \mathrm{~m} / \mathrm{s})$, slightly larger peak force central deflection is developed on the doubly laminated glass windows. However, the difference is minor. But when subjected to relatively high-velocity impact $(20 \mathrm{~m} / \mathrm{s})$, larger central deflection is found on the singly laminated glass windows. The comparisons show that the doubly laminated glass windows exhibit better resistance when subjected to relatively high-velocity windborne debris impact. It helps to prove the better performance of doubly laminated glass windows against debris impact.

\section{Conclusion}

Numerical modelling is carried out to examine the effectiveness of mitigation methods using different window supporting frame to improve the timber windborne debris impact resistance. Comprehensive numerical simulation shows that the influence of window support has a negligible influence on the forced vibration response of laminated glass windows. However, more apparent effect on the free vibration response of the laminated glass window can be found, which nevertheless is not meaningful for the penetration resistance of laminated glass windows.

Preliminary optimizing glass and interlayer pane layout is found to effectively improve the performance of laminated glass windows. Numerical simulation on singly and doubly laminated glass windows of the same total thickness show that the doubly laminated glass could effectively improve window penetration resistance. Assessment on glass pane cracking patterns and window central deflections both prove that the doubly laminated glass panels exhibit smaller central deflection and therefore better impact resistance performance.

\section{Funding Information}

This research study received no funding.

\section{Author's Contributions}

This research paper results from a joint collaboration of the involved Authors.

\section{Ethics}

The Authors declare that there are no ethical issues with the publication of this paper.

\section{References}

Alexander, C. S., Chhabildas, L. C., Reinhart, W. D., \& Templeton, D. W. (2008). Changes to the shock response of fused quartz due to glass modification. International Journal of Impact Engineering, 35(12), 1376-1385.

Beason, W. L. (1974). Breakage characteristics of window glass subjected to small missle impacts (Doctoral dissertation, Texas Tech University).

Beason, W. L., \& Morgan, J. R. (1984). Glass failure prediction model. Journal of Structural Engineering, 110(2), 197-212.

Bedon, C., Zhang, X., Santos, F., Honfi, D., Kozłowski, M., Arrigoni, M., ... \& Lange, D. (2018). Performance of structural glass facades under extreme loads-Design methods, existing research, current issues and trends. Construction and Building Materials, 163, 921-937.

Biggs, J. M. (1964). Introduction to Structural Dynamics, McGrawHill Inc. New York, New York.

Coats, D. W. (1985). Natural phenomena hazards project for department of energy sites (No. CONF-8510118--).

Dandekar, D. P., \& Beaulieu, P. A. (1995). Failure wave under shock wave compression in soda lime glass. Metallurgical and Material Applications of Shock-Wave and High-Strain-Rate Phenomena, 211-218.

Grady, D. E., \& Chhabildas, L. C. (1996). Shock-wave properties of soda-lime glass (No. SAND-96-2571C; CONF-9610170-4). Sandia National Labs., Albuquerque, NM (United States).

Griffith, A. A. (1921). VI. The phenomena of rupture and flow in solids. Philosophical transactions of the royal society of london. Series A, containing papers of a mathematical or physical character, 221(582-593), 163-198.

Hallquist, J. O. (2014). LS-DYNA® keyword user's manual: volumes I, II and III LSDYNA R7. 1. Livermore Software Technology Corporation, Livermore (LSTC), Livermore, California, 1265.

Hooper, P. A., Blackman, B. R. K., \& Dear, J. P. (2012). The mechanical behaviour of poly (vinyl butyral) at different strain magnitudes and strain rates. Journal of Materials Science, 47(8), 3564-3576.

Meng, Q., Hao, H., \& Chen, W. (2016a). Laboratory test and numerical study of structural insulated panel strengthened with glass fibre laminate against windborne debris impact. Construction and Building Materials, 114, 434-446.

Meng, Q., Hao, H., \& Chen, W. (2016b). Experimental and numerical study of basalt fibre cloth strengthened structural insulated panel under windborne debris impact. Journal of Reinforced Plastics and Composites, 35(17), 1302-1317. 
Minor, J. E., McDonald, J. R., \& Mehta, K. C. (1977) The tornado: An engineering-oriented perspective. NASA STI/Recon Technical Report N. Washington DC. https:/ui.adsabs.harvard.edu/abs/1977STIN...78312 $77 \mathrm{M} /$ abstract

Morison, C., Zobec, M., \& Frenceschet, A. (2007, September). The measurement of PVB properties at high strain rates and their application in the design of laminated glass under bomb blast. In International Symposium on the Interaction of the Effects of Munitions with Structures.

Oda, J., \& Zang, M. Y. (1998). Analysis of impact fracture behavior of laminated glass of bi-layer type using discrete element method. In Key engineering materials (Vol. 145, pp. 349-354). Trans Tech Publications Ltd.

Overend, M., Parke, G. A., \& Buhagiar, D. (2007). Predicting failure in glass - a general crack growth model. Journal of Structural Engineering, 133(8), 1146-1155.

Standards Association of Australia. (2002). AS1170.2 Structural design actions, Part2: Wind actions. https://infostore.saiglobal.com/en-us/standards/asnzs-1170-2-2002-117837_saig_as_as_246731/

US Govt. Print. Off. (1975). Interim Guidelines for Building Occupant Protection from Tornadoes and Extreme Winds: Technical Guidelines for Architects and Engineers. Defense Civil Preparedness Agency, Washington DC, United States: US Govt. Print. Off. https://tamugir.tdl.org/handle/1969.3/27090?show=full

Walker, G. R. (1991, July). The application of wind engineering technology to the mitigation of damage to housing from tropical cyclones-an Australian achievement. In Proceedings of the International Conference on the Impact of Disasters, University of California, Los Angeles, California.

Wei, J., Shetty, M. S., \& Dharani, L. R. (2006). Stress characteristics of a laminated architectural glazing subjected to blast loading. Computers \& Structures, 84(10-11), 699-707.

Yuan, Y., Xu, C., Xu, T., Sun, Y., Liu, B., \& Li, Y. (2017). An analytical model for deformation and damage of rectangular laminated glass under low-velocity impact. Composite Structures, 176, 833-843.

Zang, M. Y., Lei, Z., \& Wang, S. F. (2007). Investigation of impact fracture behavior of automobile laminated glass by $3 \mathrm{D}$ discrete element method. Computational Mechanics, 41(1), 73-83.

Zang, M. Y., Chen, H., \& Lei, Z. (2010, August). Simulation on high velocity impact process of windshield by SPH/FEM coupling method. In 2010 WASE International Conference on Information Engineering (Vol. 3, pp. 381-384). IEEE.
Zhang, X., \& Bendon, C. (2017). Vulnerability and protection of glass windows under blast: experiments, methods and current trends. International Journal of Structural Glass and Advanced Materials Research, 1(2), 10-23.

Zhang, X., \& Hao, H. (2011). Laboratory test and numerical simulation of laminated glass window response to impact and blast loads. In LABORATORY TEST AND NUMERICAL SIMULATION OF LAMINATED GLASS WINDOW RESPONSE TO IMPACT AND BLAST LOADS (pp. 705-714). CI-Premier.

Zhang, X., \& Hao, H. (2016). The response of glass window systems to blast loadings: An overview. International Journal of Protective Structures, 7(1), 123-154.

Zhang, X., Hao, H., \& Ma, G. (2013a). Laboratory test and numerical simulation of laminated glass window vulnerability to debris impact. International Journal of Impact Engineering, 55, 49-62.

Zhang, X., Hao, H., \& Ma, G. (2013b). Parametric study of laminated glass window response to blast loads. Engineering Structures, 56, 1707-1717.

Zhang, X., Hao, H., \& Ma, G. (2015a). Dynamic material model of annealed soda-lime glass. International Journal of Impact Engineering, 77, 108-119.

Zhang, X., Hao, H., Shi, Y., \& Cui, J. (2015b). The mechanical properties of Polyvinyl Butyral (PVB) at high strain rates. Construction and building materials, 93, 404-415.

Zhang, X., Hao, H., \& Wang, Z. (2015c). Experimental study of laminated glass window responses under impulsive and blast loading. International Journal of Impact Engineering, 78, 1-19.

Zhang, X., Zou, Y., Hao, H., Li, X., Ma, G., \& Liu, K. (2012). Laboratory test on dynamic material properties of annealed float glass. International Journal of Protective Structures, 3(4), 407-430. 